http://dx.doi.org/10.30681/23588403v14i0107

\title{
O EMPODERAMENTO DE MENINAS EM OMO-OBA, OBRA DE KIUSAM DE OLIVEIRA
}

\author{
Fernanda Favaro BORTOLETTO (UEM) ${ }^{1}$
}

Data de recebimento: $26 / 05 / 2020$

Data de aceite: $03 / 07 / 2020$

Resumo: Este estudo objetiva analisar o empoderamento de meninas na obra infantil "OmoOba", de Kiusam de Oliveira. A obra divide-se em seis partes que narram histórias de orixás femininos da cultura africana e afro-brasileira. Para a análise, percorre-se pela Crítica Literária Feminista no Brasil, sob a perspectiva de Zolin (2009) e a história do Movimento Feminista no Brasil, pela concepção de Duarte (2003), Ribeiro (2018) e Hooks (2015). As discussões sobre empoderamento e, consequentemente, sobre poder são pautadas em Rowlands (1997), León (2000), Moser (1989:1845) apud Rowlands (1997) e Castells (1999), sendo que o último discorre apenas sobre poder. Como se trata de uma literatura infantil, revisita-se conceitos e história da Literatura Infantil no Brasil, sob a perspectiva de Lajolo \& Zilberman (2010), Zilberman (2005), Costa (2011) e Martha (2011), além de uma biografia da autora Kiusam de Oliveira. No estudo, observou-se, principalmente, a importância da valorização das individualidades e personalidade de mulheres negras e como isso contribui para o seu empoderamento. Ao enaltecer características e qualidades de mulheres negras, a literatura de Kiusam de Oliveira é capaz de empoderar meninas e auxiliar na formação de sua identidade.

Palavras-chave: Empoderamento. Identidade. Literatura Infantil.

Abstract: This study aims to analyze the empowerment of girls in the children's book "OmoOba", by Kiusam de Oliveira. The book is divided into six parts in which narrate stories of orixás, from the African and Afro-Brazillian culture. In the analysis, the Brazillian Feminist Literary Criticism is considered, from the perspective of Zolin (2009) as well as the History of the Brazillian Feminist Movement, from the point of view of Duarte (2003), Ribeiro (2018) and Hooks (2015). The discussions on empowerment and, consequently, power, are based on Rowlands (1997), León (2000), Moser (1989:1845) apud Rowlands (1997) and Castells (1999), the latter discussing only power. As it is children's literature, the concepts and history of Brazillian Children's Literature is revisited, from the perspective of Lajolo \& Zilberman (2010), Zilberman (2005), Costa (2011) and Martha (2011), as well as a biography of the author Kiusam de Oliveira. In this study, it was observed the importance of the valorization of black women's individualities and personality, and how this contributes to their empowerment. Valuing black women's characteristics and qualities, Kiusam de Oliveira's literature is able to empower girls and help in their identity formation.

Keywords: Empowerment. Identity. Children's Literature.

\footnotetext{
${ }^{1}$ Aluna de graduação do curso de Letras Português-Inglês, da Universidade Estadual de Maringá, Maringá, Brasil, ffbortoletto@ hotmail.com.
} 


\section{Introdução}

Abordar o tema empoderamento feminino na Literatura implica em voltar olhares à origem da Crítica Literária Feminista no Brasil e entender um pouco sobre o Movimento Feminista no país. Duarte (2003) ilustra o surgimento e os desdobramentos desse movimento por meio de quatro fases, a qual denomina como ondas. É durante a última fase proposta por Duarte (2003) que a Crítica Literária Feminista surge em todo mundo, sobretudo no Brasil, alguns anos depois, como pontuado por Zolin (2009).

Faz-se necessário também considerar a vertente do Movimento Feminista que diz respeito ao feminismo negro. Ribeiro (2018) explica a origem desse movimento nos Estados Unidos e questiona a pequena quantidade de estudos que abordam esse tema crucial para o Movimento Feminista. Além disso, Hooks (2015) critica sobre a extrema inferioridade que as mulheres negras encontram-se na sociedade.

O objetivo deste artigo é discutir de que maneira o empoderamento feminino está presente na obra Omo-Oba, de Kiusam de Oliveira e analisar a importância da abordagem de temas do Movimento Feminista para a formação de meninas empoderadas e conscientes de sua posição na sociedade. Para realizar essas discussões, foram analisados os seis capítulos da obra Omo-Oba, que contam histórias de orixás da cultura africana e afro-brasileira.

A fim de discutir a respeito do empoderamento feminino, fez-se a escolha de conceituar, em primeiro lugar, identidade e poder. Dado que identidade não é algo determinado e, sim, construído, será observado neste artigo a discussão de Castells (1999) a respeito das origens da formação da identidade, fazendo uma ligação com o feminismo. Como será visto, a mulher busca no processo de individualização sua própria identidade e consegue, assim, libertar-se dos paradigmas da sociedade, alcançando nesse movimento uma transformação social na estrutura da sociedade.

Discussões de Rowlands (1997) a respeito das relações de poder, juntamente da conceituação de empoderamento feminino serão exploradas na seção "Identidade e Empoderamento". Esses dois temas serão vinculados ao final da discussão a fim de expor que para iniciar o processo de empoderamento, o sujeito necessita reconhecer e entender sua própria identidade.

Na seção "Literatura Infantil no Brasil e Kiusam de Oliveira, autora de Omo-Oba” são apresentadas considerações de Lajolo \& Zilberman (2010) e (Zilberman, 2005) acerca da história da literatura infantil no Brasil, desde sua origem até os dias atuais. Além disso, é 
apresentado um recorte da vida da escritora Kiusam de Oliveira, para contribuir com o entendimento da obra a ser analisada.

A autora Kiusam de Oliveira, em sua obra Omo-Oba, resgata suas crenças e discurso para ensinar crianças a respeito da cultura africana e afro-brasileira de modo a empoderar meninas por meio de histórias de princesas, que são representações utilizadas pela autora para explicar mitos de orixás.

\section{A Crítica Literária Feminista no Brasil como um recorte da história do Movimento Feminista brasileiro}

Ao abordar o surgimento da Crítica Feminista na Literatura no Brasil, é imprescindível a discussão a respeito da origem do Movimento Feminista em território Nacional. Duarte (2003) separa momentos importantes do movimento feminista brasileiro em diferentes "ondas", ou seja, fases. O uso desse termo é justificado pela autora pela semelhança entre a movimentação em seu interior com o fluxo das ondas, "que começam difusas e imperceptíveis e, aos poucos (ou de repente) se avolumam em direção ao clímax - o instante de maior envergadura, para então refluir numa fase de aparente calmaria, e novamente recomeçar.” (DUARTE, 2003. p. 152).

Desse modo, a autora estabelece quatro ondas do feminismo no Brasil. A primeira onda refere-se ao período de 1830, o qual as mulheres receberam o direito por lei à educação e a partir daí o surgimento dos primeiros jornais dirigidos por mulheres. Em 1870, a segunda onda caracterizou-se pelo uso da imprensa para promover apoio e uma troca intelectual entre as mulheres por meio de um surpreendente número de jornais e revistas de natureza feminista. No período da terceira onda, que compreende a década de 1920, Duarte (2003) expressa que mulheres assumem o centro das atenções ao manifestar-se pelo seu direito ao voto, os estudo superior e o direito de trabalharem em outros campos de trabalho.

Cada onda do feminismo durou cerca de cinquenta anos entre elas, assim, em 1970 surge a quarta onda, período de maiores conquistas para as mulheres. Como manifestado por Duarte (2003), a imprensa novamente abre caminhos para a expressão de mulheres, com a criação de jornais e periódicos dirigidos por mulheres que abordavam temas como sexualidade, questões raciais, o espaço da mulher em artes como literatura, teatro e cinema etc.

Durante essa fase, cargos políticos, eleições e posições de poder começam a ser ocupadas por mulheres. A autora ainda revela que diversas organizações conscientizam-se a respeito da condição discriminatória que as mulheres se encontram e demandam o seu direito 
de visibilidade e de melhores condições trabalhistas. Nesse contexto a ONU define o dia 8 de Março como o Dia Internacional da Mulher.

Zolin (2009) explica que o processo de conquista de novos lugares na sociedade implica no surgimento de cada vez mais pesquisas e congressos ministrados por mulheres a respeito da Literatura e Crítica Literária não só no Brasil, como em outros países do mundo. Nesse contexto, a autora pontua que Kate Millet, dá origem à Crítica Feminista nos Estados Unidos com a publicação de sua tese de doutorado Sexual Politics, em 1970. Segundo Zolin, a Crítica Feminista no Brasil teria surgido a partir de , com a criação de associações e grupos de pesquisa sobre a mulher no campo da Literatura, tais como o GT Mulher e Literatura da Associação Nacional de Pós-Graduação e Pesquisa em Letras e linguística e o Seminário Nacional Mulher \& Literatura.

Segundo Ribeiro (2018), o movimento do feminismo negro fortalece-se nos Estados Unidos entre 1960 e 1980, durante a segunda onda do feminismo, com a fundação da National Black Feminist, uma organização criada em 1973 que discutia questões sobre as mulheres negras nos Estados Unidos. A partir de então, feministas negras iniciaram seus escritos, criando uma literatura feminista negra. No entanto, a autora afirma que nas obras brasileiras sobre o feminismo, é difícil encontrar estudos sobre o feminismo negro.

A autora Zolin (2009) apresenta que atualmente as linhas de pesquisa da área da Crítica Feminista abrangem investigações a respeito do gênero na literatura e sua construção e representação, a revisão do cânone e a busca de novos saberes de inclusão nele com o resgate de obras desconhecidas de autoria feminina, e o desenvolvimento de reflexões teóricas a partir de concepções de identidade e diferenças.

\section{Identidade e Empoderamento}

Com as discussões a respeito das diferenças surge a necessidade de estabelecer o conceito de identidade. Manuel Castells (1999), em sua obra intitulada "O Poder da Identidade", estabelece que a identidade não é estabelecida através de regras impostas por instituições da sociedade, mas os próprios sujeitos a constroem no processo de individualização. Dessa forma, o processo de formação da identidade é motivada por fatores como história, geografia, memória coletiva e religião, fatores os quais são "processados pelos indivíduos, grupos sociais e sociedades, que organizem seu significado em função de tendências sociais e projetos culturais enraizados em sua estrutura social, bem como em sua visão de tempo/espaço" (CASTELLS, 1999. p.23). 
Com o propósito de descobrir quem constrói a identidade coletiva e para qual finalidade, Castells (1999) discute três origens da construção da identidade, que são: Identidade legitimadora, Identidade de resistência e Identidade de projeto. A primeira diz respeito àquela estabelecidas pelas instituições dominantes da sociedade com o objetivo de propagar a sua dominação para os outros indivíduos do meio social. A identidade de resistência é originada pelos indivíduos em condição desvalorizada pelos grupos dominantes, criando resistências com ideias diferentes dos presentes na sociedade. O terceiro tipo de identidade é "quando os atores sociais, utilizando-se de qualquer tipo de material cultural ao seu alcance, constroem uma nova identidade capaz de redefinir sua posição na sociedade e, ao fazê-lo, de buscar a transformação de toda a estrutura social" (CASTELLS, 1999. p.24).

$\mathrm{O}$ autor ainda revela que o feminismo é um caso do processo Identidade de projeto, pois ao lutar contra o patriarcalismo, consequentemente, vai contra todos os conceitos historicamente ditados pela sociedade a respeito da reprodução, personalidade e sexualidade. Dessa forma, o feminismo toma como princípio a condição oprimida da mulher para realizar transformações na sociedade, construindo uma nova identidade para a mulher, que, com isso, consegue estabelecer a sua libertação e dos outros indivíduos da sociedade.

O conceito de Identidade dialoga com o conceito de Empoderamento, pois o sujeito ou grupo social que percebe, após o processo de individualização, construindo sua identidade, que o que ele é destoa dos padrões socialmente impostos, ele pode, a partir daí, iniciar um processo de valorização pessoal, se tornando um agente ativo a fim de modificar os conceitos estruturais da sociedade que o colocam em posição marginalizada.

Antes de trazer a definição de empoderamento em si, faz-se importante expressar os conceitos de poder. Segundo Rowlands (1997), existem quatro relações de poder: o poder sobre, o poder para, o poder com e o poder de dentro. O "poder sobre" diz respeito da capacidade de um indivíduo ou grupo tomar uma decisão, agindo contra os interesses de outros, causando uma situação de conflito. O segundo tipo de poder apresentado pela autora trata-se de um poder produtivo, capaz de estimular outros indivíduos, elevando seu ânimo e abrindo-lhes novas possibilidades. O "poder com" evidencia a ideia de que um grupo pode possuir mais força do que a soma das partes individuais, sobretudo em relação ao solucionamento de problemas de modo conjunto. Por fim, a última forma de poder apontada por Rowlands (1997) é o "poder de dentro", que se relaciona com a habilidade de resistir ao poder dos outros, demonstrando respeito e aceitação própria.

Desse modo, León (2000) pontua que a mulher tem sido alvo do tipo de "poder sobre", o poder controlador, e é por isso que ela encontra-se em uma situação de desempoderamento. 
Mas, segundo a autora, isso não significa que ela não possui poder algum, apenas indica que a sua posição social exprime pouco poder e que em seu meio há limitações rigorosas. Em outras palavras, nesse modelo de poder a mulher é capaz de tomar algumas decisões, mas não consegue perceber sua própria capacidade de ocupar lugares de fala e de tomada de decisão justamente por conta da posição social limitadora que se encontra. A autora, então, defende que a mulher se empodere com uma nova concepção de poder.

Assim, o empoderamento feminino é definido por Moser (1989:1845) apud Rowlands (1997) como a capacidade das mulheres de ampliar sua autoconfiança e força pessoal, possibilitando-as de definir suas escolhas na vida e de controlar os recursos materiais e imateriais. No entanto, Rowlands (1997) declara que o empoderamento individual não é suficiente, mas apenas um meio de atingir o empoderamento coletivo. Dessa maneira, a autora apresenta a ideia de que para o empoderamento é necessário:

Assumir o controle de suas próprias vidas para estabelecer suas próprias agendas, organizar-se para ajudar-se umas às outras e aumentar as ordens de apoio ao Estado e de mudança para a sociedade. Com o empoderamento coletivo das mulheres, a direção e os processos de desenvolvimento podem ser transformados para responder às suas necessidades e perspectivas. $\mathrm{O}$ empoderamento coletivo das mulheres indubitavelmente produzirá o empoderamento individual das mulheres, mas não apenas a nível do progresso individual. (YOUNG, 1993, p.159 apud ROWLANDS, 1997, p. 217-218, tradução da autora $)^{2}$

Por fim, considera-se importante fazer uma ligação entre empoderamento e identidade, pois acredita-se para que o indivíduo ou o grupo, aqui mais especificamente a mulher, comece o processo de empoderamento pessoal, é necessário, primeiramente, o reconhecimento de sua posição dentro da sociedade e da condição sócio-histórica e política que as mulheres foram e são submetidas até os dias atuais, para então ser capaz de empoderar-se e ajudar outras mulheres nesse processo. Em outras palavras, a mulher necessita reconhecer sua identidade para, então, empoderar-se e começar a provocar mudanças na estrutura da sociedade tradicionalmente patriarcal.

\section{Literatura Infantil no Brasil e Kiusam de Oliveira, autora de Omo-Oba}

\footnotetext{
${ }^{2}$ Asumir el control sobre sus propias vidas para sentar sus propias agendas, organizarse para ayudarse unas a otras y elevar demandas de apoyo al Estado y de cambio a la sociedad. Con el empoderamiento colectivo de las mujeres, la dirección y los procesos del desarrollo pueden ser transformados para responder a sus necesidades y perspectivas. El empoderamiento colectivo de las mujeres producirá, sin lugar a dudas, el empoderamiento individual de las mujeres, pero no sólo a nivel de progreso individual. (YOUNG, 1993, p.159 apud ROWLANDS, 1997, p. 217-218,)
} 
O início da Literatura Infantil no Brasil deu-se no final do século XIX e início do século XX, período o qual não havia uma produção verdadeiramente brasileira, pois os livros para o público infantil eram obras estrangeiras que foram traduzidas para a língua portuguesa e chegavam ao território nacional através de Portugal.

Desse modo, as autoras Lajolo \& Zilberman (2010) elucidam que intelectuais, escritores e educadores iniciaram uma tarefa patriótica de estímulo à produção de literatura infantil, com obras como Histórias de Nossa Terra (1907), de Júlia Lopes de Almeida e Através do Brasil (1910), de Olavo Bilac e Manuel Bomfim que contavam com a transmissão de um sentimento de na valorização não só do país, mas no enaltecimento da natureza e suas riquezas e da língua nacional..

As autoras estabelecem que essa realidade apenas se modificou com o início do Modernismo no Brasil, quando Monteiro Lobato surge para dar voz às crianças, garantindo-as um status maior na sociedade. Lobato acreditava que era necessário escrever obras em uma linguagem que realmente interessasse o público infantil e, assim, publica, em 1921, Narizinho Arrebitado, que rapidamente tornou-se sucesso de vendas. Portanto, de acordo com Zilberman (2005), Monteiro lobato rompe com a tradição literária infantil vigente até então, que pautavase em obras adaptadas de outras adaptações e que falavam "de um mundo sem qualquer vínculo com a possível experiência do leitor" (Zilberman, 2005, p. 156), e renova a linguagem e as atitudes das figuras heróicas do passado. A partir desse momento, a produção de obras voltadas às crianças alavancou no Brasil e escritores que geralmente produziam obras voltadas para o público adulto, como José Lins do Rego, Graciliano Ramos, Erico Veríssimo e Cecília Meireles, escreveram histórias infantis.

As influências do célebre escritor Monteiro Lobato podem ser vistas nas obras infantis mais contemporâneas, que começam a destacar a situação atual do Brasil, abordando temas com críticas sociais como a miséria, violência, injustiça, poluição da natureza, entre outros, conforme enfatizado por Lajolo \& Zilberman (2010). Além disso, a ilustração ganha importância, deixando de ser um mero acessório na obra, tornando-se uma parte fundamental e autônoma dentro da obra infantil.

Ademais, autora Martha (2011) discute que a literatura na atualidade ocupa-se em abordar os mais variados temas, inclusive os tradicionalmente ocultados dos leitores jovens como morte e perda, sexualidade, identidade, violência etc. Assim, segundo Costa (2011) a literatura infantil, que em primeiro momento tinha somente o objetivo de educar a criança, ganham uma nova função de suma importância: 
Informar e educar passam a ser pano de fundo do interesse de autores e obras, afinal a aventura do conhecimento humano não dispensa narrativas interessantes e com doses de valorização do imaginário. Mas, em primeiro plano, estão o autoconhecimento do leitor, o entretenimento (chamado, por vezes, de prazer), o experimentalismo na linguagem narrativa e o lúdico. (COSTA, 2011, p.104)

Para a autora, as funções da literatura infantil no Brasil atualmente estendem-se para além da educação formal. Informar e educar é do interesse de autores e obras, mas, em primeiro plano, estão o autoconhecimento do leitor, o entretenimento (chamado, por vezes, de prazer), o experimentalismo na linguagem narrativa e o lúdico.

Nesse contexto contemporâneo, a obra Omo-Oba, publicada em 2009 por Kiusam de Oliveira, narra seis histórias diferentes da cultura africana e afro-brasileira de orixás que representam divindades do gênero feminino: Oiá, Oxum, Iemanjá, Olocum, Ajê Xalugá e Ododuá. A autora contempla essas divindades como princesas, trazendo como tema comum de todas as histórias o empoderamento de meninas.

Nascida em Santo André, no estado de São Paulo, Kiusam Regina de Oliveira, autora das obras infantis Omo-Oba (2009), O Mundo no Black Power de Tayó (2013) e O Mar que Banha a Ilha de Goré (2014), possui Mestrado em Psicologia e Doutorado em Educação pela Universidade de São Paulo e atua na área da educação há vinte e cinco anos.

Além de sua vocação na escrita, Kiusam de Oliveira é bailarina e por meio dessa arte e através da expressão da corporeidade afro-brasileira, procura gerar reflexões a respeito da desconstrução do corpo que foi socialmente imposto pela sociedade brasileira. O tema da corporeidade e dança afro-brasileira, relações étnico-raciais e cultura são temas frequentes em suas palestras que são realizados por todo o Brasil.

Em suas três obras de literatura infantil e infantojuvenil, Kiusam de Oliveira dá vida a personagens que discutem temas contemporâneos, relacionando com raízes africanas e afrobrasileiras. Assim, como escritora, Kiusam de Oliveira preocupa-se em apresentar para as crianças histórias que trazem um discurso comprometido com o empoderamento do corpo e das identidades negras, além de atentar-se ao empoderamento feminino e à promoção de uma educação antirracista. Assim, representando o universo africano e afro-brasileiro de maneira inovadora e lúdica, Kiusam de Oliveira é capaz de atingir todos os públicos, com crianças de todas os gêneros, idades e etnias.

\section{O Empoderamento Feminino em Omo-Oba}


A autora Kiusam de Oliveira escreve seis pequenos contos para narrar as histórias tradicionais de orixás, divindades dos povos africanos e afro-brasileiros. Esta seção é destinada à análise de cada uma das histórias que compõem a obra Omo-Obá, atentando-se em discutir a respeito da identidade e do empoderamento feminino.

As divindades que a autora decide abordar em sua obra são orixás femininos e para apresentá-los a autora utiliza a figura de princesas, que são retratadas como crianças, possivelmente para criar um apelo ao público infantil na questão da identificação da criança com o texto lido. Zilberman (2005) defende que quando se centraliza a história ao redor de um personagem infantil, "o leitor encontra um elo visível com o texto, vendo-se representado no âmbito ficcional" (ZILBERMAN, 2005, p. 73) e, com isso, interessa-se pela leitura, aproximando-se da literatura. A autora transforma essas antigas divindades em princesas porque elas não são adultas ainda, caso o contrário seriam rainhas e, assim, reconta histórias tradicionais com situações típicas do universo infantil, com as personagens entretendo-se com brincadeiras. As ilustrações de Josias Marinho também contribuem com a representação da criança na obra ao criar belas e coloridas imagens das personagens com suaves traços infantis.

A primeira história, entitulada “Oiá e o búfalo interior”, narra a história da princesa Oiá conhecida pelas suas características de determinação, graça e genialidade, que tinha o poder de transformar-se em animais. Nesse episódio, enquanto brincava com seu amigo Ogum precisou sair às pressas e ir em direção da floresta a fim de cumprir uma tarefa. A curiosidade de seu amigo fez-o entrar na floresta para segui-la e lá encontrou um búfalo filhote que, rapidamente, revelou a princesa Oiá por baixo de sua pele. Ela então revela seu segredo, fazendo uma reflexão acerca do poder que cada mulher tem:

Toda menina, toda mocinha e toda mulher tem dentro de si a força e o poder de um animal selvagem sagrado que, em certos momentos, devem ser colocados para fora, devem explodir para o universo com a mensagem de que fazemos parte de tudo isso. Quando colocamos essa força para fora, muitos meninos e meninas, mocinhos e mocinhas, homens e mulheres não compreendem e, por isso, devemos mantê-la em segredo. (OLIVEIRA, 2009, p.15)

A autora, ao trazer esse discurso na fala de uma personagem infantil, busca mostrar a força da mulher aos pequenos leitores, sobretudo a importância de expressar esse poder para a sociedade. Ao mencionar que muitas pessoas não entendem a expressão dessa força da mulher, Oliveira remete à sociedade patriarcal atual, que limita o poder das mulheres ao considerar a figura do homem como hierarquicamente superior à da mulher. Assim, a autora inicia na primeira história uma espécie de raciocínio que será continuado ao longo das outras seis 
histórias, que possibilita os leitores a assimilação do valor e poder não só da mulher enquanto adulta, mas também como criança.

Em "Oxum e seu mistério" encontra-se a história da divindade Oxum, cuja beleza e vaidade eram características que a definiam. No conto, seu amigo Ogum, responsável por construir objetos de ferro, cansa-se do trabalho e retira-se para a floresta para morar, afastando todos que tentassem dissuadi-lo de voltar para a cidade. Apesar de todos os homens duvidarem da capacidade de Oxum, deixaram-na tentar trazê-lo de volta e, assim, ela vestiu belas e perfumadas roupas, soltou seus cabelos e foi à sua missão. Logo que começou a dançar e exalar seu perfume, Ogum ficou completamente hipnotizado, e ela pediu às abelhas para que derramassem mel em suas mão para dar ao menino. A princesa conduziu Ogum de volta para a cidade com sua dança e canto enquanto colocava mel na boca de Ogum e, assim, toda cidade celebrou Oxum.

Oliveira traz uma personagem negra como sendo símbolo de beleza e vaidade e cumpre com o papel de mostrar toda a beleza e poder que uma mulher negra possui, evidenciando a formosura de Oxum e "seus lindos cabelos negros e crespos" (OLIVEIRA, 2009, p. 20), a graça de seus movimentos e o delicioso perfume que exalava. A beleza dessa personagem foi capaz de encantar não só o menino, mas também tudo a seu redor: "As abelhas, encantadas com a beleza de Oxum e com a delicadeza com que havia feito o pedido, abriram uma fenda na colmeia e o mel começou a escorrer nas mão de Oxum" (OLIVEIRA, 2009, p. 21).

Bell Hooks (2015), defende que a mulher negra se encontra em uma posição de extrema inferioridade na sociedade:

Como grupo, as mulheres negras estão em uma posição incomum nesta sociedade, pois não só estamos coletivamente na parte inferior da escada do trabalho, mas nossa condição social geral é inferior à de qualquer outro grupo. Ocupando essa posição, suportamos o fardo da opressão machista, racista e classista. (HOOKS, 2015, p. 207)

Para a autora, as mulheres negras estão hierarquicamente abaixo dos homens negros e também das mulheres brancas, indivíduos já marginalizados na sociedade, estando sempre em posição de oprimidas.

Outro ponto a ser analisado é o fato de Oxum, ao demonstrar seu poder, consegue provar a todos que ela, como menina, é capaz de fazer qualquer coisa, realizando triunfalmente missões que nenhum homem foi capaz de conseguir. Nesse sentido, o episódio de Oxum relaciona-se com o anterior ao apresentar homens inferiorizando a figura da mulher por não compreender, ou não aceitar, que ela é competente o suficiente para realizar feitos importantes, ou seja, demonstrar seu poder. 
Em "Iemanjá e o poder da criação do mundo" observa-se a história da Rainha do Mar que tinha como poder a capacidade de "criar dentro dela, as estrelas, as nuvens e os orixás" (OLIVEIRA, 2009, p. 24). Iemanjá vivia no òrun, o céu ou mundo espiritual das religiões afrodescendentes, e ao perceber sua solidão, Olodumare-Olofim, conhecido como Ser Supremo e criador de todos os orixás e homens, decide presentear a menina. Então, faz duas tentativas frustradas de trazer companhia para Iemanjá, com estrelas e nuvens, mas logo que elas saíam da boca da menina, após Olodumare colocar suas mãos sobre a barriga dela, elas iam rapidamente embora para o céu. Para resolver o problema, Olodumare criou rios e oceanos repletos de conchas, corais e estrelas do mar e ofereceu à princesa como morada e, por fim, com um toque em sua barriga, de sua boca "saíram diversos seres protetores, os orixás, com a incumbência de povoarem o planeta Terra. Nasceram Ossaim, Oxóssi, Ogum, Xangô, Obaluaiyê e os Ibejis. Assim, a princesinha Iemanjá não ficaria mais só” (OLIVEIRA, 2009, p. 28).

Nessa história, observa-se a posição de uma mulher como criadora de elementos do mundo e, principalmente, de outros orixás. Iemanjá tem o poder de criar novas divindades, representando o poder da maternidade e a importância do papel da mulher como geradora de novas vidas e de todas as vidas que existem no mundo.

Em seu dicionário dos símbolos, CHEVALIER, \& GHEERBRANT (1982) definem que a figura da mãe representa o calor, a ternura, a segurança de estar sob um abrigo e de ter alimento. É relevante destacar que Kiusam de Oliveira retrata o reconhecimento e o amor dos seus filhos ao final do conto, quanto todos celebram a princesa Iemanjá. Esse momento de dar valor à mulher que gerou todos é extremamente significativo para expressar a importância que as mães possuem e que deveriam receber na sociedade

O quarto capítulo da obra, denominado "Olocum e o segredo do fundo do oceano", trata-se da narração da linda e misteriosa princesa Olocum, que mantinha sua real identidade em segredo: ao anoitecer seu corpo de mulher transformava-se em um corpo de sereia, era uma anfíbia. Ela gostava de Ocô, mas receava o que aconteceria se ele soubesse de seu segredo, porém, logo que tornaram-se amigos, ela revelou seu mistério. Ocô ridicularizou a princesa e contou seu segredo a todos. Envergonhada, Olocum fugiu para o fundo do mar e jurou viver lá para o resto da vida, ou até conseguir recuperar-se para poder voltar para a terra.

Observa-se nesse conto a preocupação em promover a auto-aceitação e mostrar a importância de voltar olhares a si mesmo a fim de refletir sobre quem cada um é. A característica da introspecção é por vezes tratada como uma traço negativo, como pode ser visto no conto, já que Olocum é retratada como introspectiva, o que deixava todos intrigados e 
curiosos para descobrir seu segredo. Entretanto, possuir esse feitio foi fundamental para que a princesa fosse capaz de refletir e perceber que era necessário aceitar sua própria natureza: “Por que só eu sou assim? Tenho que aceitar minha natureza, não tenho como modificar isto. Preciso encarar de frente: eu sou uma anfíbia” (OLIVEIRA, 2009, p. 32).

Após revelar sua identidade e ser rejeitada por todos, ela continuou fiel consigo mesma e soube reconhecer que se os outros não estavam preparados para lidar com ela, Olocum também não faria esforços para ser alguém que ela não é. Então, entendendo que o problema não era com ela, e sim com os outros, a princesa se refugia no fundo do mar a fim de viver na solitude, novamente voltando-se a si mesma.

O capítulo seguinte conta a história “Ajê Xalugá e seu brilho intenso", ela era irmã de Iemanjá e era muito bonita e vaidosa. Como reinava apenas uma parte do oceano, quando Olocum ia para a terra, ela aproveitava para visitar e descobrir novas partes do oceano, brincando nas ondas e disfarçando-se de espuma brilhante. Um dia Olocum voltou ao mar antes do esperado e pegou Ajê Xalugá e ao descobrir que ela emitia um brilho intenso, lançou a seguinte profecia: “O que você der aos outros retornará a você; esse será o seu segredo, mas todo segredo guarda um perigo, nunca se esqueça disso" (OLIVEIRA, 2009, p. 39). A princesa ficou animada com a profecia e decidiu sair para nadar, exibindo seu brilho poderoso, mas acabou cegando as pessoas que olharam para seu brilho. Como profetizado, Ajê Xalugá também ficou cega e Iemanjá levou-a para o fundo do mar para cuidar dela para o resto dos dias, vivendo felizes juntas cavalgando nas ondas.

Observa-se aqui a história de uma menina cheia de curiosidade e vivacidade que mesmo após uma tragédia que desabilitou sua visão não perdeu sua esperança e sua positividade. Após não ouvir o conselho de uma força superior a ela, Ajê Xalugá sofreu as consequências de seus atos, mas não se entregou à tristeza, apenas adotou uma nova perspectiva: “- Iupi!! Que delícia é cavalgar nas pontas das ondas disfarçada de espuma, só que, agora, menos brilhante.” (OLIVEIRA, 2009, p. 40). A autora, possivelmente, deseja passar aos leitores a ideia de que independente da dificuldade que as pessoas são submetidas, é necessário manter-se forte e sempre procurar o lado positivo da situação.

É interessante notar a descrição da princesa feita pela autora no início da narração: “Ajê Xalugá tinha como atributos a beleza, a vaidade, a impetuosidade, a curiosidade, o empoderamento, o orgulho, a determinação e a coragem" (OLIVEIRA, 2009, p. 35). A palavra “empoderamento" é trazida grafada em itálico no texto, possivelmente para dar uma ênfase nessa característica dentre todas as outras citadas. Imagina-se que o pequeno leitor que ainda 
não conhece o significado desse termo, procure descobrir seu sentido, perguntando aos familiares ou procurando espontaneamente em um dicionário ou em computadores.

Outro aspecto marcante desse conto, que também se repete nas outras histórias, é o uso de características atípicas do estereótipo feminino ao descrever a princesinha. Em geral, a figura da mulher é comumente retratada como sendo frágil, gentil e educada, características que são esquecidas da obra de Kiusam de Oliveira, que descreve as princesinhas como guerreiras, determinadas, geniais, corajosas, impetuosas, entre outros. Esse fato é imprescindível para quebrar com a percepção de que mulher precisa ser completamente passiva para que seja considerada bela. Oliveira procura mostrar para o público infantil que beleza é seguir e acreditar em quem cada um é e que todos podem ser o que quiserem, independente do seu gênero.

Assim como em toda história narrada na obra, são evidenciadas características físicas inerentes às mulheres negras, como a menção dos cabelos negros e crespos ao descrever as princesas e a sua caracterização nas ilustrações de Josias Marinho com lábios bem delineados e grossos e com nariz tendo a base mais larga. Essa reiteração contribui com a ideia do empoderamento da mulher negra transmitido pela obra, enaltecendo sua beleza e qualidades, criando um senso de identidade para o pequeno leitor. Retomando a ideia de "Identidade de projeto", proposta por Castells (1999), Oliveira utiliza a figura da mulher negra oprimida socialmente em sua literatura para construir uma identidade coletiva, capaz de dialogar com os leitores e auxiliar na formação individual de sua identidade.

O último capítulo, intitulado "Oduduá e a briga pelos sete anéis" narra a história da criação do Céu e da Terra, segundo a tradição afrodescendente e afro-brasileira. Ododuá vivia em uma cabaça com o príncipe Obatalá e, como o espaço era pequeno, eles precisavam dormir um em cima do outro. O príncipe sempre decidia que seria ele quem dormiria no lado de cima, apesar de todas as objeções da princesa sobre como seria mais justo uma decisão comum. Um dia, receberam sete anéis de presente e Obatalá apossou-se de quatro anéis, deixando Oduduá com apenas três, o que fez a princesa decidir lutar contra ele para pegar os anéis de volta. Durante a árdua briga, a cabaça se rompeu em duas partes e "a parte de cima dela foi projetada para o espaço, juntamente com o príncipe Obatalá; e a parte de baixo permaneceu lá com a princesa Ododuá" (OLIVEIRA, 2009, p. 45), a partir de então, eles prometeram olhar-se para sempre.

Neste capítulo, é visível a ideia da opressão masculina sobre a mulher, já discutida anteriormente. Obatalá, por ser homem acreditava que merecia privilégios e recusava-se a tratar sua companheira Oduduá com igualdade. É notável o empoderamento da princesinha, que não entendia ou aceitava essa inferização que estava submetida e então decide lutar pelo que 
acreditava. Ao ir contra o poder opressor, ela consegue libertar-se e conquista seu espaço, não precisando mais viver guiada por decisões tomada por homens.

Esse último conto ilustra perfeitamente o conceito de empoderamento feminino proposto por Moser (1989:1845) apud Rowlands (1997), pois Oduduá busca em sua própria força interior um meio de conquistar o espaço que merece, modificando assim toda a estrutura daquele ambiente em que morava.

\section{Considerações Finais}

A cada página da obra Omo-Oba são evidenciadas características físicas inerentes às mulheres negras, como a menção dos cabelos negros e crespos ao descrever as princesas e a sua caracterização nas ilustrações de Josias Marinho com lábios bem delineados e grossos e com nariz tendo a base mais larga. Da mesma forma, são ressaltadas as individualidades e personalidade dessas mulheres, que não só são caracterizadas como fortes, inteligentes, determinadas e corajosas, mas também estão a todo momento demonstrando esses atributos em suas ações. Essa reiteração contribui com a ideia do empoderamento da mulher negra transmitido pela obra, enaltecendo sua beleza e qualidades, criando um senso de identidade para o pequeno leitor. Retomando a ideia de "Identidade de projeto", proposta por Castells (1999), Oliveira utiliza a figura da mulher negra oprimida socialmente em sua literatura para construir uma identidade coletiva, capaz de dialogar com os leitores e auxiliar na formação individual de sua identidade.

Assim, a autora Kiusam de Oliveira, por meio da promoção do empoderamento individual de meninas, atinge também o empoderamento coletivo, que como Rowlands (1997) pontua é completo. Portanto, ao escrever sua obra, a autora possibilita o entendimento da importância do feminismo para todas as mulheres e auxilia no processo de reconhecimento do valor da mulher e da importância de cada um.

\section{Referências}

CASTELlS, Manuel. O Poder da Identidade. São paulo: Paz e Terra, 1999.

CHEVAliER, J.; GHEERBRANT, A., Dictionnaire des Symboles. Paris: Éditions Robert Laffont S.A et Éditions Jupiter, 1982.

COSTA, Marta Morais da. A narrativa infantil brasileira. p.101-122. In: MARTHA, Alice Áurea Penteado (Organizadora). Tópicos de literatura infantil e juvenil. Maringá: Eduem, 2011. 
DUARTE, Constância Lima. Feminismo e literatura no Brasil. Estud. av., São Paulo , v. 17, n. 49, p. 151-172, dez. 2003 . Disponível em: < http://www.scielo.br/scielo.php?script=sci arttext\&pid=S0103-

40142003000300010\&lng=pt\&nrm=iso >. Acesso em: 21 jun. 2019.

HOOKS, Bell. Mulheres negras: moldando a teoria feminista. Rev. Bras. Ciênc. Polít.[online]. 2015, n.16 [cited 2019-06-28], pp.193-210. Available from: $<$ http://www.scielo.br/scielo.php?script=sci_arttext\&pid=S0103-

33522015000200193\&lng=en\&nrm=iso>. ISSN 0103-3352. http://dx.doi.org/10.1590/0103335220151608 .

KIUSAM de Oliveira. Literafro, 2018. Disponível em: < http://www.letras.ufmg.br/literafro/autoras/1055-kiusam-de-oliveira $>$. Acesso em: 21 jun. 2019.

LAJOLO, Marisa; ZILBERMAN, Regina. Literatura Infantil Brasileira: História e Histórias. 6. ed. São Paulo: Ática, 2010.

LEÓN, Magdalena. EMPODERAMIENTO: RELACIONES DE LAS MUJERES COM EL PODER. Revista Estudos Feministas, Florianópolis, v. 8, n. 2, p. 191, jan. 2000. ISSN 18069584. Disponível em: 〈https://periodicos.ufsc.br/index.php/ref/article/view/11935>. Acesso em: 21 jun. 2019. doi:https://doi.org/10.1590/\%x.

MARTHA, Alice Áurea Penteado. A narrativa juvenil brasileira contemporânea. p.123-134. In:

MARTHA, Alice Áurea Penteado (Organizadora). Tópicos de literatura infantil e juvenil. Maringá: Eduem, 2011.

OLIVEIRA, Kiusam de. Omo-Oba: histórias de princesas. Belo Horizonte: Mazza Edições, 2009.

RIBEIRO, Djamila. Quem tem medo do feminismo negro?. 1. ed. — São Paulo : Companhia das Letras, 2018.

ROWLANDS, Jo. Empoderamiento y Mujeres Rurales en Honduras: Un Modelo para el Desarrollo. p. 213-245. In: LEÓN, Magdalena (Compiladora). Poder y Empoderamiento de las Mujeres. Colombia: Tercer Mundo S.A., 1997.

ZILBERMAN, Regina. A Literatura Infantil na Escola. 11. ed. rev. e ampl. São Paulo: Global, 2005.

ZOLIN, Lúcia Osana. Crítica Feminista. p. 217-242. In: BONNICI, Thomas; ZOLIN, Lúcia Osana (Orgs.). Teoria Literária: abordagens históricas e tendências contemporâneas. 3. ed. rev. e ampl. Maringá: Eduem, 2009. 